\title{
Antonio Campaña
}

\section{Mario Ferrero, un nuevo poeta}

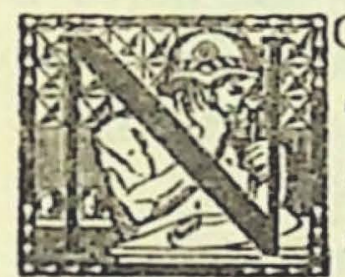

HACE mucho Fernando Alegría ha considerado la conveniencia de observar la poesía chilena a través de su proceso histórico (1) y otorga a la tradición poética nacional el valor fundamental para cl estudio de esta parte de la estética. Singularmente, el fino ensayista y estudioso que es Alegría, ha clavado en la raíz misma de lo que se ha dado en llamar el hecho poético de Chile. Debe ser por ello que a veces hablamos de nuestra tradición poética con pródiga palabra, al parecer ello nos procura cierto orgullo hacerlo aunque el atisbo de su origen sea nebulosa perenne, nos interesa sacar una reputación más distinguida; de cualquier manera, no hay duda de que debemos convenir en que no existe más que esta verdad única aplicada a la poesía chilena: ella se alza en vuelo trascendente, sube hasta la cima que hoy ostenta y que nos hace volvernos hacia nosotros mismos y hablar de tradición mediante el logro de todas sus generaciones y no sólo-como en ocasiones se teoriza - de uno que otro poeta a quien el tiempo no ha sido capaz de amputar nada de su situación propia.

Esta tradición viviente, humana, que nos viene de siempre, la vamos viendo también ahora - grandes afortunados- en la obra inMéxico.

(1) Fernando Alegría, La Poesía Chilena, Ed. Fondo de Cultura Económica, 
tensa, en el afán cotidiano de nuestros poetas; llegamos a palpar sus vigilias creadoras y el vaho tibio que escapa de una labor reciente. Si el pasado no fue estéril, si no sólo hay islas gratas para afirmar responsabilidades, ni hay demasía presente sin pasado, sino que, por el contrario, hay el rumor del océano, la sensación ambiental de afirmarse en el mar como manifestación de lo preterido, construir con la amenaza de su torrente y caudales sobrecogedores, con su terrible acicate.

Y qué mal se acepta a estos hacedores de nuestra continuidad poética, a estos aventajados de la aventura que designan una fecha viva en la amplitud del tiempo para la poesía chilena.

No podemos precisar por qué, pero cada vez que la figura o el nombre del poeta Mario Ferrero nos preocupa, sea por sus libros o por su incesante quehacer, por su estructura gremial superconsciente, un acto de rebeldía social, que tal vez su vigoroso accionar intensifica, nos hace asociar nuestro gran hecho poético, lo que nos aventuramos a clasificar como la tradición viviente, a la sequedad del medio con sus poetas. La evolución humana de Ferrero tiene el poder de sumar simpatías y algo más, no se sabe qué, pero donde, seguramente, hay contagio y disposiciones de arraigo familiar para entender su actitud y conmoción frente a los problemas que enfrenta su persistencia.

La quietud no es una situación confortable para el poeta, una especie de temporal le anima, como fidedigno amador del mar que es, para luchar por aquellas inasibles realidades sociales del escritor. Antes de publicar su primer libro, Capitanía de la Sangre, funda un grupo inquieto, donde hay un tanto de aquelarre fundamentalmente humano: en esa intimidad no se plasman aventuras siniestras, sujeciones a un arquetipo poético secreto, ni se siguen escuelas o tendencias que los animadores del grupo rechazaban por comprender muertos los movimientos de poesía, viajando hacia nosotros nada más en su papel histórico, de erupción conveniente, pero apagada; la aventura que no puede sostener por más tiempo su sortilegio frente 
a la presión infatigable del orden, como señala Guillermo de Torre (2) y mucho antes de él un poema de Apollinaire, "La Linda Pelirroja":

Yo sé sobre lo antiguo y lo nuevo todo lo que un hombre sólo [podxía saber de ambos

$Y$ sin preocuparme ahora de esta guerra

Entre nosotros y para nosotros amigos mios

Juzgo esta larga disputa entre la tradición y la invención

Entre el orden y la aventura

Vosotros cuya boca está hecha a imagen divina

Boca que es el propio orden

Sed indulgentes cuando nos comparáis

Con los que fueron la perfección del orden

$A$ nosotros que buscamos la aventura en todas partes

Este accionar en sentido estricto promueve sólo expectativas a sus poetas, pero han de ser éstos los que edifiquen su propia obra en total libertad y la obra del propio Ferrero es la encargada de afirmar este aserto: una inquietud social que, invariablemente, pesa en su poesía, es el legado más importante del poeta a su grupo, en el cual, en contraposición a él, se dan voces tesoneras pero desvaídas.

A pesar de que Capitanía de la Sangre no acusa todavía el impacto de su pensamiento social, el poeta trabaja en las reivindicaciones del escritor con tenacidad ejemplar y en la divulgación de los nuevos valores de la poesía.

Este vitalismo del poeta con que se levanta ante la vida, su inquietud que le subyuga con relaciones distintas, impregna su poesía de agitadas renovaciones. Ferrero condiciona su arte al hallazgo de su raíz y capa por capa va desligándose del asedio terrible que soporta en su evolución porque es un nos Aires.

(2) Guillermo de Torre, La Aventura y el Orden, Edit. Losada, 1943, Bue- 


\section{Centinela inconcluso en la aguja del ansia}

(“Capitanía de la Sangre").

Es evidente en la poesía de este poeta, a vista primera, un estado de honrada continuidad, de agitada variedad rechazadora de la quietud complacida.

En cierto modo es lo que, también, avista Dámaso Alonso cuando estudia la poesía de Gerardo Diego y le llama la atención en el poeta - sobre cualquier otra cualidad-su variación de variaciones. Es decir, el pleno desasosiego, cierto estado de mutabilidad inferido, la expectativa huidiza, el afán de innovar, la eterna y cósmica búsqueda.

No es, ciertamente, el mismo caso: nuestra relación es formal y aclaratoria y no manifiesta ni una comparación ni una despersonalización. El español aguarda dádivas intelectuales (analogía con la poesía fría) en una explotación - al parecer- de las formas para la forma dentro de la más prudente imprudencia. En cambio, Mario Ferrero, entre las dos caras de la moneda no es ninguna de las dos: es el canto, el borde que rueda, la angustia, por lo establecido en su sangre y por la ordenación del mundo en un plúmbeo caos:

La sensación de paz nace en el vidrio

Si pero yo estoy hecho de contradicciones

Me duele este silencio vegetal

Con su árbol apagado y sus pájaros

Solos como la noche sola

("Capitanía de la Sangre”).

En Ferrero la variación la determina una razón superior y su actitud es la rebeldía en movimiento, una ebullición que, en vez de malograr su aventura con la poesía, va situándola más allá de todo refugio permanente en saludable braceo.

¿Pero cuál es esta razón superior del poeta que, incluso, le lleva 
a surcar aguas comprometedoras para su poesía, a pesar de que ella prueba y establece su trascendencia y su inequívoca sinceridad?

La respuesta no es difícil; ahí está, determinante supremo, su poema clave, "Capitanía de la Sangre", que otorga el título al mismo libro:

Si pero yo estoy hecho de contradicciones

¡Qué manera tan simple en el decir; es el lenguaje que habla con sus signos más elementales! El poeta sufre el ser y mantiene el conflicto. Va contra el orden impuesto porque acarrea un cataclismo como bagaje, personal indumentaria para traspasar la realidad; ahí está su hecho esencial, su interioridad profunda, su objetivación anímica.

Está singularmente hecho de contradicciones, de pliegues sensibles y, claro, su combustión necesita salidas urgentes, de prisa, que modifican su apostura a través del movimiento expresivo.

El poeta no puede dejarse vivir y Mario Ferrero no podía escapar a su posibilidad de ser, de quebrar las situaciones presentes y vadear las evasiones por cuanto deberá hacerse (3) en aspiraciones inmediatas, de activo militante de sus interiores.

Y su variación de variaciones, la zona influenciante, sería lo que le duele, la obstinada huella que persigue en incontenibles intentos:

Me duele hasta la sombra obstinada y sencilla

Los nidos de la sal donde me duermo

Los párpados del éter que camino

Salian de mi alma volando los murciélagos

(3) Robert Campbell, Jean-Paul Sartre o una Literatura Filosofica, página 48, Edit, Argos, Buenos Aires. 
Una noche muy honda me clavaron sus capas

Llegaron con sus cofres de silencio

$Y$ sus macabros pies que se adivinan

Fabricaron su casa de gas lento

Sus bocas de presagios colgaron de las islas

Era un tiempo de sangre $y$ de torcidas voces

El día navegaba sobre una flecha pura

("Capitanía de la Sangre").

El poeta necesita ir ajustándose cada vez más y debido a ello camina sobre los párpados del éter como por una materia transmutadora; sabe que entre los individuos es el menos falible y el más recibidor y transmitivo; su modificación, el ajuste, viene a representar una cualidad de perfección y de responsabilidad dominante, como el troquelador absoluto que enjuicia con su punto de vista personal los hombres y las cosas y, después de advertirlas por su conocimiento, a la vez ingenuo y pleno de fuerza mágica, las hace reductibles a su uso a través de un vínculo de excepción que es su materia unitaria evidentísima.

En "Capitanía de la Sangre" advertimos más que un supuesto juego metafórico que viene a ser exactamente lo mismo que sujetarse a la novedad y expresarse en función de ella. Es cierto que el poeta se abandona en ocasiones - y qué poeta no lo hace en mayor o menor escala siempre- a dilucidar situaciones de tipo emocional por medio de una imaginería pura, alterando como sucederá obligadamente en tales casos la experiencia de las respectivas emociones. Sin embargo, estas alternativas no prevalecen en la generalidad de la obra, la cual acusa una profunda característica humana dentro de el principal sentido de individuación, aquel ajustarse insinuante y permanente que es su rasgo propio y que señala una poesía alterada y movediza aún sobre la huella huidobriana que deja pasar a veces: 
Yo estoy aqui y en todas partes

Un ruiseñor so desnuda en las noches para volar

Me coloca un cojín bajo los sueños

Después abre la puerta de mi oreja y se va

("Capitanía de la Sangre").

No hay duda que predomina en estos versos la impronta del autor de Altazor; en Ferrero el ruiseñor se desnuda en la noche para volar y en Huidobro se sitúa en su garganta; las puertas que este último precisa son para el mar, y Ferrero las supone humanas, partícipe anatómica, con condición de vida, lo cual vitaliza mucho más la metáfora en su relación independiente, la personaliza, como en Huidobro es más viviente aquella que objetiva el instante del ruiseñor, situado en la garganta y no en la noche.

Siempre he creido mucho más en las afirmaciones de los poetas sobre la poesía que en las de un especialista crítico. El poeta auténtico vive un estado poético, hecho que encierra una síntesis mágica de una serie de procesos supervalorativos de su condición especial, y el especialista, en cambio, se adjudica estas experiencias de lo emocional y de lo bello, sólo de segunda mano, por recepción y apreciación. Cualquier definición de poesía hecha por un poeta, por absurda que ella pueda aparecer a simple vista, es mucho más honda y clava en lo profundo del conocimiento poético con mayor autenticidad que la del crítico, quien siempre habrá de luchar contra esa frontera esquiva de la experiencia. Novalis al expresar que "sólo el artista puede adivinar el sentido de la vida", debe haber estado pensando en un poeta como representante de ese artista. $\mathrm{Y}$ algo de esto mismo es lo que, seguramente, sabía Lautreamont cuando se dolía de Boileau y motejó a Sainte-Beuve como el Suicida para Reir.

En el caso de Mario Ferrero, el poeta ha definido su obra en forma acertada y tienen vigencia aún para su poesía posterior la sínțesis de sus impresiones del fenómeno poético que, como Poesía y 
Estética, se publican en 1948 (4). A través de ellas es posible advertir su concepción de la ilimitada función del creador y cree que ella "siendo la suma de las experiencias humanas y estéticas del hombre y su máxima expresión, es esencial y fatalmente social”. El poeta comprende la estimación consciente que corresponde al creador y la práctica activa a que somete su esfuerzo por objetivar su realidad, no la realidad de los demás porque el creador se está viviendo en una experiencia de significación por su personalidad. Me interesan éstas y otras observaciones de Ferrero en torno al problema poético - empleamos la palabra problema para enjuiciar el estado actual de la poesía como también el calificativo de fenómeno poético, porque ambos, situacionalmente, corresponden a un propósito de dilucidación- como estimativas en nuestro interés por La Noche Agónica. Ferrero, en sus juicios sobre poesía y estética, agrega, además: "La poesía es para mí la suma de las preguntas eternas, una búsqueda desesperada, el supremo intento de definir lo indefinible. El proceso mismo de la creación poética me parece un sortilegio de maravilla, puramente intuitivo, totalmente ajeno al mecanismo de la razón. Por esto, todo poema íntimamente logrado, es necesariamente hermoso. No creo en la belleza de inventario, estática, inmutable. La belleza es un movimiento y la poesía es la resultante de una suma de movimientos que ascienden de lo subjetivo a lo objetivo, del ser al espacio y del espacio al tiempo".

Nos dan deseo de agregar aquella definición extraordinaria de Pablo de Rokha: "Al poema como al candado es menester echarle llave" y la otra, no menos fundamental, de Pfeiffer cuando explica que toda auténtica poesía, que todo poema íntimamente logrado, es intraducible $\mathrm{y}$ en esta intraducibilidad consiste una de las mejores pruebas de su constitución o personalización.

Sin embargo, dos de los antecedentes de la poesía y estética de Mario Ferrero gravan la poesía de La Noche Agónica: aquella con-

(4) Hugo Zambelli, Trece Poetas Chilenos, Valparaíso, 1948. 
dición fatalmente social y un supremo intento de definir lo indefinible. La obra oscila entre estas dos situaciones del poeta:

Alli van por las plazas las ojeras de fieltro soplando un cuero hinchado de alfileres y pitos. Alli van por las calles con sus bolsas de vino, allí están en los circos, en las mesas de juego, sudando gota a gota una mirada espesa. Y atraviesan la noche sus fantasmas de cera $y$ van a las bodegas con paso de murciélago y se asoman llorando al balcón de los miedos. Alli están en el aire, en las ferias del pueblo, y el hombre huele a esperma y a marea, a grandes rebanadas de fatiga que golpean el día como una puerta nueva.

("Los cretinos iluminados")

y desde el lado de un sentido de individuación:

Oigo pasar el tiempo por una red callada. Siento el mar a lo lejos como un gran agujero, una escala golpeada de manchas y varillas, las sábanas del hombre donde crece la angustia como un ramo de tigres.

Y la mosca esperando entre los huesos el día de los charcos, del barro y la fatiga.

("Los pasos blancos")

Estos trozos de poemas de La Noche Agónica son dos indicios de la poesía de Mario Ferrero, dos aproximaciones de lo que vendría a constituir su mundo poético dentro de las nuevas promociones de poetas chilenos. No estamos aquí, por supuesto, ni midiendo ni pesando materiales y mucho menos cambiando o permutando contribuciones sobre tema tan vario y alterable sino exponiendo ante- 
cedentes y relacionando más o menos algunos hechos que permitan una ubicación a determinado poeta, como es el caso de Ferrero.

En estos poemas - y en otros también - hay una acusación nerudiana que contradice, en parte, su sentido aséptico, ya que Ferrero a pesar de esa variación de variaciones, de su heredad transmutable, es un poeta consciente, y ya hemos dicho en otra parte que todo poeta auténtico lo es. Es el Neruda de garra vencedora, de patética absorción, de Las alturas de Macchu Picchu, siempre presente en gran cantidad de poetas chilenos nuevos:

\section{Del aire al aire, como una red vacía}

Pero el tema fundamental de esta poesía de Mario Ferrero en La Noche Agónica es el problema del hombre, su desamparo total, el intento por modificar hasta sus cimientos la actual estructura social que le rodea; su angustia está más bien referida a este ámbito imperativo, sojuzgante, que remece su condición humana y establece una variante fuerte para su poesía, un dolor que reencuentra en su convivencia solitaria o en el tumulto:

Desde mañana marcharé con ellos.

Iremos por el mar cortando leña

para hacer nuestra casa en la colina.

$Y$ otra vez en la tarde, entre canciones,

bajaremos al mar a buscar las gavillas.

(“Al mar los leñadores").

Pero el que siempre canta la realidad, también se mira. En esta poesía, sin duda, es el hombre en su problematicidad y sus asuntos externos, llámase sociales, quien se sitúa primordialmente, en el centro del instinto del poeta, mas no alcanza a velar del todo la cualidad primigenia del amor, su roce que franquea un tope de masa tibia, una vital categoría de formas y aguijones: 
Como un perpetuo silbo bajo el agua, como una lanza tibia, me llegan desde lejos tus senos de almidón y gritería, tu crespo pie dormido, tus tatuajes, tus anillos de sangre serpentina...

y más adelante:

Yo no sé cuánto tiempo dura el rojo abanico de tu agua moribunda sobre el ruido del pelo. Yo no sé en qué dominio de canto y geometría van cayendo tus labios como flor calcinada, tus gotas de canela, tus lentos ventanales. Sólo sé que me duele tu arena en el espejo, que estoy solo y vacío, como un vino quemado. $Y$ que una vez te quise $y$ ardian los veranos entre las altas hojas de un armario.

("El signo vacío").

El amor establece un sitio en esta poesía atormentada de Mario Ferrero, aunque delimite su cauce por asideras realidades. El amor no es un sueño que quema sus raíces, ni las flotantes sombras que le rodean y castigan; por el contrario el poeta transita una orilla eminentemente naturalista, el lento río de los sentidos con su agobiante gratuidad y entrega.

Sin embargo, el deslinde devuelve el amor al sitio donde servirá las instancias apacibles de su propio ciclo y Mario Ferrero retoma - ¿lo dejó alguna vez? - el cauce de la realidad pugnaz, vivencialismo ilusionado que el poeta no abandona en la efervescencia de su movilidad y nos entrega, como acción vital, Las. Lenguas del Pan, libro esperado de Ferrero, que avanza entre sus anteriores revelaciones una mayor claridad temática y formal.

El poeta se considera a sí mismo como el más útil de los hom- 
bres y se atribuye utensilios salvadores, en los cuales se mezcla algo de mágico o adivinación constante. Por ello, el juego a que está destinado en la sociedad es el más alto y, al mismo tiempo, el más peligroso. Ferrero considera que el devenir histórico ha lanzado sobre los hombros del poeta una misión sublime: frente al caos él debe alzar su palabra lúcida, bañada por la más pura verdad, ser el portador de una nueva conciencia de la libertad. Y entonces su poesía, hecha desde lo alto, ensimismada en la luz, lanza relámpagos de veracidad enamorada:

En la espuma del sol

la juventud danzaba.

Era su pie una cinta de rocio,

un anillo de azúcar la esperanza.

De alli nació de nuevo

la eterna raza humana,

otra vez nació el pan de la ceniza

$y$ de la pólvora fue creciendo el agua.

("Las Banderas").

El poeta considera que cualquier movimiento expresivo puede ser bueno y adaptarse a tal o cual forma de sentir; de esta manera, la pluralidad sentida por el poeta nos llevaría a considerar que determinada actitud poética - búsqueda de lo que llamaríamos la verdad poética- puede ser auténtica si el poeta logra traducirla en verdadera poesía. Del mismo modo, tendríamos que convenir que ninguna poesía se compromete si es verdadera y que toda falsa poesía nace comprometida.

Acorde a estos conceptos, Ferrero utiliza en Las Lenguas del Pan viejas formas que retoma actualizándolas, a las que adensa en un mundo de alegría vital, clarísimo. Un ejemplo de ello es la "Ronda del Sol": 
Arriba vagabundos,

levantarse a vagar,

que el dia es un camino alegre $y$ sin trabajo,

un camino infinito que pasa por el mar.

Subamos a la cumbre donde el viento se agita,

subamos a cantar.

Arriba, despertad,

que viene el día niño

con su rubio reloj acrisolado

y el pecho colorado

como la loica infanta del lugar.

Arriba, que os traigo las noticias

de la aurora bravia,

los racimos, los besos,

los jugos de alquería,

la melena del mar.

La simplicidad de esta poesía, que nos hace pensar en el juglar que se halla en su verdadero juego, es motivo de ahondamiento en Ferrero. Su neopopularismo es -ya lo dijimos- más vital cuanto más claro. El movimiento expresivo se hace así diáfano y su encuentro con la utilidad poética, lo único que cuenta, se realiza mediante un encadenamiento suave, de conseguida armonía, arquitectural, pleno, a pesar de aquellos momentos en que prima una ironía cortante, de plúmbeo ademán satírico.

No obstante, en Las Lenguas del Pan observamos que algunos poemas se vuelven, sólo en lo formal, hacia unas redes que Ferrero parece no haber abandonado: el mundo nerudiano, con su viscosidad deslumbrante:

Piedra y más piedra sobre el aire hundido. A su reseca piel de ojeras verdes como un toro anegado va cayendo la brisa, 
el sudor de las razas horadando los muros, la sangre temblorosa en los nudos sulfúricos, los pasos solitarios que despiden el sol.

("Río de Cobre").

Desde luego, este retorno hacia una zona superada - ni a esa otra un tanto olvidada, pero viva, de Miguel Hernández- no alcanzan a rozar, siquiera, la intimidad de esta poesía; por el contrario, Las Lenguas del Pan, reafirma la fuerte condición poética del arte de Mario Ferrero, poeta uncido a su canto, a su fidelidad pura, en el cual su amor a lo verdaderamente digno emerge de su origen como en estos hermosos versos de su poema "Hablando estoy de Chile en Primavera":

Desde el limite norte hasta las hebras

de la antártica noche transparente, vienen los hombres de morena frente a ofrecerte sus puños de ginebra. 